\title{
Spectral domain optical coherence tomography in children: normative data and biometric correlations
}

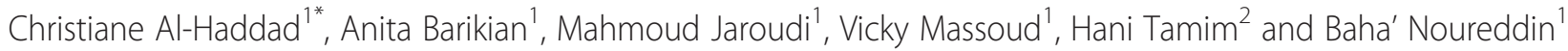

\begin{abstract}
Background: The aim was to report normative values of retinal nerve fiber layer (RNFL) and macular parameters in children using spectral domain optical coherence tomography (OCT) and to perform correlations with age, refractive error and axial length.

Methods: This was an observational cross-sectional study recruiting 113 healthy children aged 6 to 17 years with no ocular abnormality except refractive error. After a comprehensive eye examination and axial length measurement, RNFL and macular thickness measurements were performed using the Cirrus OCT machine. Main outcome measures were macular volume, macular thickness and RNFL thickness values as well as their correlations with age, refractive error and axial length. Right eyes of all subjects were selected for analysis.

Results: One hundred and eight children were included in the study, 65 females and 43 males. Mean age was $10.7+/-3.1$ years, average spherical equivalent refraction (SE) was $-0.02+/-1.77(-4.25$ to +5.00$)$ diopters and average axial length was $23.5+/-1.0$ (21.5 to 25.8$) \mathrm{mm}$. Mean RNFL thickness was $95.6+/-8.7 \mu \mathrm{m}$, average macular thickness was $279.6+/-12.5 \mu \mathrm{m}$, central macular thickness was $249.1+/-20.2 \mu \mathrm{m}$, and mean macular volume was $10.1+/-0.5 \mathrm{~mm}^{3}$. Central macular thickness values were significantly higher in males $(p<0.001)$. RNFL measurements did not correlate with age but did show a positive correlation with SE. All macular parameters were consistently positively correlated with age and most of them were positively correlated with SE. When controlling for axial length, only the macular inner circle thickness was positively correlated with age.
\end{abstract}

Conclusions: Using Cirrus OCT, normative RNFL and macular parameters in healthy children below 18 years of age were established; measurements varied by age and gender.

Keywords: Optical coherence tomography, Pediatric, Retinal nerve fiber layer, Macular thickness, Biometric correlations

\section{Background}

Optical Coherence Tomography (OCT) is a noninvasive, noncontact, transpupillary imaging method that performs objective high-resolution cross-sectional images of retinal tissue. The recently introduced spectral domain OCT (SD-OCT) provides measurements of the retinal nerve fiber layer (RNFL) and macula with greatly improved image acquisition speed and image resolution up to $5 \mu \mathrm{m}$

\footnotetext{
*Correspondence: ca12@aub.edu.lb

${ }^{1}$ Department of Ophthalmology, American University of Beirut, Beirut, Lebanon

Full list of author information is available at the end of the article
}

[1]. This is particularly helpful when applying this technology in uncooperative children.

Several studies have proved the feasibility of OCT in the pediatric population [2-9]. Nevertheless, all OCT devices have an integrated normative database only for adult subjects 18 years of age and older. Earlier studies have reported normative values in children using the time domain OCT (TD-OCT) devices [3-11]; similar reports using SD-OCT are much less available. Although RNFL measurements taken from TD-OCT and SD-OCT are comparable, significant differences exist and values cannot be used interchangeably $[12,13]$. Comparing macular thickness between the two instruments is even 
more complicated, being dependant on pathology and location [14]. Measurement protocols vary even among different SD-OCT instruments [15]. Only a few studies in the literature aimed at reporting normative reference ranges using SD-OCT [16-21]. Normative measurements in children using Cirrus are least reported, especially with regards to macular parameters.

The clinical applications of SD-OCT are increasingly expanding [22]; normal reference values for RNFL and macular thickness are needed in the pediatric population where the software has no nomogram for comparison. The purpose of this study was to collect normative values for SD-OCT measurements of macular thickness and volume and peripapillary RNFL thickness in healthy eyes of normal children using the most recent commercially available Cirrus SD-OCT, and to study the effects of age, gender, axial length, and refractive error on these values.

\section{Methods}

\section{Study population}

This was a cross-sectional study of healthy white Middle Eastern children 6 to 17 years of age visiting the pediatric ophthalmology clinic at the American University of Beirut from November 2011 to September 2012. This group of children were referred because of failed school screening, visual behavior abnormalities noted by parents, positive family history of refractive errors, or referral from the pediatrician. The study was approved by the American University of Beirut Institutional Review Board. Written parental informed consent was obtained from parents or legal guardians; children and adolescent assent forms were also provided for children 7 years of age and older. One hundred and thirteen children and adolescents were enrolled prospectively and consecutively. Detailed demographic data were obtained during the clinic encounter. Included in the study were subjects with no ocular abnormality except refractive error less than 7.00 diopters (of hyperopic or myopic spherical equivalent), normal visual acuity (best corrected Snellen visual acuity of 20/20) and normal fundoscopy. Excluded were patients with a history of intraocular surgery, strabismus, anisometropia more than 1.50 diopters, amblyopia, retinal pathology, glaucoma, optic nerve cup to disc ratio $>0.5$ or asymmetry of $>0.2$ between fellow eyes. Patients with history of prematurity, neurologic, metabolic or other systemic diseases were also excluded.

\section{Ocular examination}

All subjects received a comprehensive ophthalmologic examination by a pediatric ophthalmologist (CA). The visual acuity of each eye was recorded using the Snellen chart; intraocular pressure assessment, motility examination, stereoacuity testing, slit lamp exam, cycloplegic refraction, and dilated fundoscopy were performed. Pupils were dilated using cyclopentolate $1 \%$ eyedrops, instilled twice 10 minutes apart. Manual retinoscopy was performed 30 minutes after the last drop by a pediatric ophthalmologist (CA). This was also confirmed by automated refraction (Canon RK-F1 autorefractor; Canon, Tokyo, Japan). Right eyes of all subjects were used for analysis and underwent axial length measurements and OCT imaging. Axial length (AL) measurements were obtained using the IOL master (Carl Zeiss AG, Oberkochen, Germany). Multiple AL measurements (at least 3) were taken and an average value was recorded.

\section{Spectral domain OCT imaging}

Cirrus HD-OCT (Carl Zeiss, Dublin, California, USA) device was used to obtain high-definition images. Macular cube $512 \times 128$ and optic disc cube $200 \times 200$ were utilized to assess macular and peripapillary RNFL thickness respectively. Macular thickness (average, central, and all subfields) and volume and RNFL thickness (all four quadrants: superior, nasal, inferior and temporal, as well as average) were recorded. Signal strength of 6 or higher was considered acceptable. Internal fixation was used to ensure proper alignment of the eye. All imaging was performed by an experienced ophthalmic photographer or one of the authors. Multiple measurements were taken and the best centered one with good signal strength was chosen for analysis. The macular analysis provided measurements of central subfield thickness (central $1 \mathrm{~mm}$ disc) as well as macular thickness in two concentric circles of $3 \mathrm{~mm}$ and $6 \mathrm{~mm}$ diameters respectively centered at the fovea. The inner and outer circles were in turn divided into four quadrants: superior, nasal, inferior and temporal according to the nine areas A1-9 corresponding to the Early Treatment Diabetic Retinopathy Study (ETDRS Research Group 1985).

\section{Statistical analysis}

Data were entered in a Microsoft Excel sheet, and then transferred to the Statistical Package for Social Sciences program (SPSS, version 19) for data management and analyses. Descriptive statistics were reported as mean and standard deviation, as well as the $5^{\text {th }}$ and $95^{\text {th }}$ percentiles. Distributions of the measurements were graphically presented using histograms. Moreover, correlation between different measurements was done using the Pearson correlation coefficients. Finally, to adjust for the potentially confounding effect of age, gender, and axial length, we carried out multivariate linear regression analyses, where the regression coefficient was reported along with the 95\% confidence interval (CI). Paired t-test was used to compare macular thicknesses. P-value $<0.05$ was considered to indicate statistical significance. 

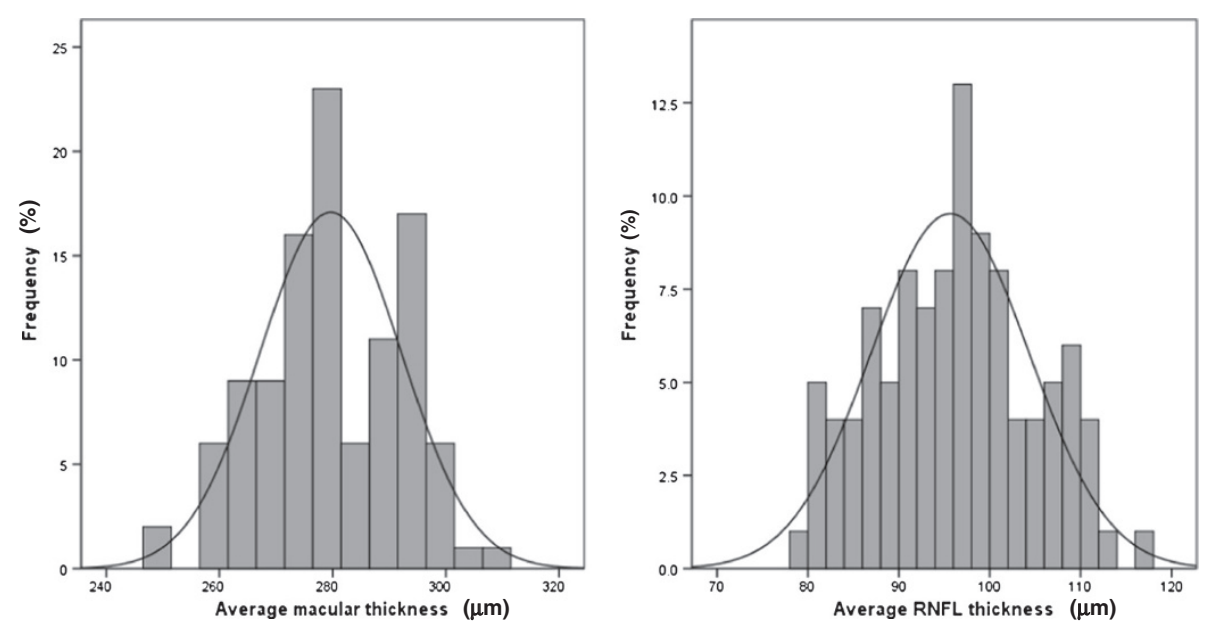

Figure 1 Normal distribution of average macular thickness (left) and average retinal nerve fiber layer thickness (right). RNFL, retinal nerve fiber layer.

\section{Results}

A total of 113 children and adolescents were enrolled in the study, five subjects were later excluded due to decentered OCT scans. We included 108 patients (mean age $10.7+/-3.1$ years), 43 males (mean age $10.7+/-3.4$ years) and 65 females (mean age 10.7+/-3.0 years). Data from right eyes of all patients were recorded for analysis. Average spherical equivalent (SE) refraction was $-0.02+/-1.77$ $(-4.25$ to +5.00$)$ diopters and average axial length was 23.5+/-1.0 (21.5 to 25.8) $\mathrm{mm}$.

Mean RNFL and macular thicknesses followed a normal distribution (Figure 1). Patients were divided into four subgroups based on age: 6 up to 9 years of age $(n=$ 35), 9 up to12 years $(n=28), 12$ up to15 years $(n=28)$ and 15 up to18 years $(\mathrm{n}=17)$. Mean RNFL thickness for all patients was $95.6+/-8.7 \mu \mathrm{m}$; quadrant thicknesses followed a pattern similar to that in adults with the thickest being the inferior followed by superior then nasal then temporal (Table 1).

Mean central macular thickness for all patients measured $249.1+/-20.2 \mu \mathrm{m}$, while average macular thickness value was $279.6+/-12.5 \mu \mathrm{m}$, and mean macular volume was $10.1+/-0.5 \mathrm{~mm}^{3}$ (Table 2). Inner circle values were significantly increased as compared to the outer macular thicknesses $(p<0.0001)$. There was a significant positive correlation between average RNFL and average macular thickness $(\mathrm{r}=0.30, \mathrm{p}=0.002)$.

As expected, in the correlation analysis, a significant negative correlation was seen between age and $\mathrm{SE}(\mathrm{r}=-0.33$, $\mathrm{p}=0.001)$ and between $\mathrm{SE}$ and $\mathrm{AL}(\mathrm{r}=-0.70, \mathrm{p}<0.001)$. A significant positive correlation was observed between age and AL ( $\mathrm{r}=0.30, \mathrm{p}=0.02)$.

On multivariate analysis, RNFL measurements were not affected by gender whereas central macular thickness values were significantly increased in males $(\mathrm{p}<0.001)$. RNFL measurements did not correlate with age but did correlate positively with SE. When controlling for axial length, the correlation with SE remained significant for average RNFL thickness but not for quadrant thicknesses. All macular parameters were consistently positively correlated with age and most were positively correlated with SE (Table 3).When controlling for axial length, correlation with SE was lost and only the positive correlation of the inner circle macular thicknesses with age persisted.

Table 1 Distribution of retinal nerve fiber layer thickness measurements using Cirrus optical coherence tomography

\begin{tabular}{|c|c|c|c|c|c|}
\hline & All ages & $6-9 y$ & $9-12 y$ & $12-15 y$ & $15-18 y$ \\
\hline Measurements in $\mu \mathrm{m}$ & $\begin{array}{l}\text { Mean }\left(5^{\text {th }}-95^{\text {th }}\right. \\
\text { percentile })\end{array}$ & $\begin{array}{l}\text { Mean }\left(5^{\text {th }}-95^{\text {th }}\right. \\
\text { percentile) }\end{array}$ & $\begin{array}{l}\text { Mean }\left(5^{\text {th }}-95^{\text {th }}\right. \\
\text { percentile })\end{array}$ & $\begin{array}{l}\text { Mean }\left(5^{\text {th }}-95^{\text {th }}\right. \\
\text { percentile })\end{array}$ & $\begin{array}{l}\text { Mean }\left(5^{\text {th }}-95^{\text {th }}\right. \\
\text { percentile) }\end{array}$ \\
\hline Superior & $121(99-145)$ & $123(99-151)$ & $118(96-142)$ & $122(102-145)$ & $117(93-131)$ \\
\hline Nasal & 70 (49-94) & 70 (49-89) & $71(51-83)$ & $71(49-95)$ & $69(43-113)$ \\
\hline Temporal & $66(54-84)$ & $69(56-87)$ & $64(51-83)$ & $68(57-83)$ & $63(53-75)$ \\
\hline Inferior & $125(95-159)$ & $129(91-163)$ & $122(101-150)$ & $127(95-160)$ & $118(97-131)$ \\
\hline Average & $96(80-111)$ & $98(84-111)$ & $93(80-106)$ & $98(82-111)$ & $92(80-101)$ \\
\hline
\end{tabular}

y, years. 
Table 2 Distribution of macular measurements using Cirrus optical coherence tomography

\begin{tabular}{|c|c|c|c|c|c|}
\hline & All ages & $6-9 y$ & $9-12$ y & $12-15 y$ & $15-18 y$ \\
\hline Measurements & $\begin{array}{l}\text { Mean }\left(5^{\text {th }}-95^{\text {th }}\right. \\
\text { percentile) }\end{array}$ & $\begin{array}{l}\text { Mean }\left(5^{\text {th }}-95^{\text {th }}\right. \\
\text { percentile) }\end{array}$ & $\begin{array}{l}\text { Mean }\left(5^{\text {th }}-95^{\text {th }}\right. \\
\text { percentile) }\end{array}$ & $\begin{array}{l}\text { Mean }\left(5^{\text {th }}-95^{\text {th }}\right. \\
\text { percentile) }\end{array}$ & $\begin{array}{l}\text { Mean }\left(5^{\text {th }}-95^{\text {th }}\right. \\
\text { percentile) }\end{array}$ \\
\hline Macular Volume, $\mathrm{mm}^{3}$ & $10.1(9.3-10.7)$ & $10.0(9.0-10.7)$ & $10.0(9.3-10.7)$ & $10.2(9.3-10.8)$ & $10.2(9.5-11.0)$ \\
\hline \multicolumn{6}{|l|}{ Macular thickness, $\mu \mathrm{m}$} \\
\hline Central & 249 (219-285) & $244(204-284)$ & $243(205-262)$ & $255(223-288)$ & $259(226-296)$ \\
\hline Average & $280(259-298)$ & $277(250-296)$ & $278(260-297)$ & $281(257-304)$ & $283(263-306)$ \\
\hline \multicolumn{6}{|l|}{ Inner Circle } \\
\hline Superior & $321(294-348)$ & $315(288-344)$ & $318(290-340)$ & $327(303-356)$ & $329(301-355)$ \\
\hline Nasal & $321(294-347)$ & $315(291-338)$ & $317(282-339)$ & $327(304-358)$ & $329(308-361)$ \\
\hline Temporal & $309(282-337)$ & $304(276-328)$ & $306(279-331)$ & $313(289-342)$ & $314(281-340)$ \\
\hline Inferior & $318(293-343)$ & $313(290-336)$ & $315(286-339)$ & $324(301-350)$ & $321(295-346)$ \\
\hline \multicolumn{6}{|l|}{ Outer Circle } \\
\hline Superior & $282(260-308)$ & $283(256-311)$ & 279 (262-299) & $285(259-321)$ & $284(288-300)$ \\
\hline Nasal & $298(272-322)$ & $295(271-317)$ & $297(272-316)$ & $303(278-328)$ & $300(272-327)$ \\
\hline Temporal & $263(242-287)$ & $261(237-288)$ & $260(241-279)$ & $269(241-339)$ & $265(243-288)$ \\
\hline Inferior & $270(247-295)$ & $268(245-298)$ & $267(248-288)$ & $257(255-301)$ & $268(246-291)$ \\
\hline
\end{tabular}

Table 3 Multivariate regression analysis of optical coherence tomography parameters by age and spherical equivalent

\begin{tabular}{|c|c|c|c|c|c|c|}
\hline \multirow[b]{2}{*}{ Measurements } & \multicolumn{3}{|c|}{ Age } & \multicolumn{3}{|c|}{ Spherical equivalent } \\
\hline & $\begin{array}{l}\text { Regression } \\
\text { coefficient }\end{array}$ & $\begin{array}{l}\text { 95\% Confidence } \\
\text { interval }\end{array}$ & $P$ value & $\begin{array}{l}\text { Regression } \\
\text { coefficient }\end{array}$ & $\begin{array}{l}\text { 95\% Confidence } \\
\text { interval }\end{array}$ & $P$ value \\
\hline \multicolumn{7}{|l|}{ RNFL thickness, $\mu \mathrm{m}$} \\
\hline Superior & -0.19 & -1.08 to 0.7 & 0.67 & 2.09 & 0.53 to 3.65 & 0.009 \\
\hline Nasal & 0.47 & -0.32 to 1.27 & 0.24 & 3.10 & 1.69 to 4.5 & $<0.0001$ \\
\hline Temporal & -0.59 & -1.18 to 0.00 & 0.05 & -0.69 & -1.74 to 0.35 & 0.19 \\
\hline Inferior & 0.07 & -0.97 to 1.12 & 0.89 & 5.22 & 3.37 to 7.06 & $<0.0001$ \\
\hline Average & -0.01 & -0.51 to 0.49 & 0.96 & 2.48 & 1.59 to 3.37 & $<0.0001$ \\
\hline Macular Volume, $\mathrm{mm}^{3}$ & 0.03 & 0.002 to 0.06 & 0.03 & 0.07 & 0.02 to 0.12 & 0.007 \\
\hline \multicolumn{7}{|l|}{ Macular Thickness, $\mu \mathrm{m}$} \\
\hline Central & 1.82 & 0.64 to 2.99 & 0.003 & -0.41 & -2.49 to 1.67 & 0.70 \\
\hline Average & 0.95 & 0.16 to 1.74 & 0.02 & 1.82 & 0.43 to 3.21 & 0.01 \\
\hline \multicolumn{7}{|l|}{ Outer circle } \\
\hline Superior & 0.97 & 0.09 to 1.85 & 0.03 & 3.11 & 1.55 to 4.66 & $<0.0001$ \\
\hline Nasal & 1.06 & 0.15 to 1.97 & 0.02 & 1.79 & 0.18 to 3.39 & 0.03 \\
\hline Temporal & 1.23 & 0.17 to 2.28 & 0.02 & 1.69 & -0.18 to 3.57 & 0.07 \\
\hline Inferior & 0.66 & -0.25 to 1.57 & 0.16 & 1.77 & 0.16 to 3.38 & 0.03 \\
\hline \multicolumn{7}{|l|}{ Inner circle } \\
\hline Superior & 1.85 & 0.90 to 2.79 & $<0.0001$ & 1.52 & -0.15 to 3.18 & 0.07 \\
\hline Nasal & 1.91 & 0.95 to 2.86 & $<0.0001$ & 1.07 & -0.61 to 2.74 & 0.21 \\
\hline Temporal & 1.47 & 0.55 to 2.38 & 0.002 & 1.19 & -0.43 to 2.80 & 0.15 \\
\hline Inferior & 1.40 & 0.45 to 2.29 & 0.003 & 0.73 & -0.86 to 2.32 & 0.37 \\
\hline
\end{tabular}

RNFL, retinal nerve fiber layer.

Bolded $\mathrm{p}$ values are statistically significant, $\mathrm{p}<0.05$. 
Table 4 Reported retinal nerve fiber layer thickness measurements by optical coherence tomography in normal children

\begin{tabular}{|c|c|c|c|c|c|c|c|c|}
\hline \multirow[b]{2}{*}{ OCT } & \multirow[b]{2}{*}{ Source } & \multirow[b]{2}{*}{$\mathbf{n}$} & \multirow[b]{2}{*}{ Age, years* } & \multicolumn{5}{|c|}{ Mean RNFL values, $\mu \mathrm{m}^{*}$} \\
\hline & & & & Average & Superior & Nasal & Temporal & Inferior \\
\hline \multicolumn{9}{|l|}{ TD-OCT } \\
\hline \multirow[t]{2}{*}{ ОСТ 3} & \multirow[t]{2}{*}{ Ahn 2005} & \multirow[t]{2}{*}{72} & \multirow[t]{2}{*}{$12.6 \pm 2.1$} & \multirow{2}{*}{$\begin{array}{l}\text { OD106.8 } \pm 13.0 \\
\text { OS104.3 } \pm 7.7\end{array}$} & OD $132.7 \pm 23.9$ & OD $75.6 \pm 13.6$ & OD $85 \pm 14.9$ & OD $133.3 \pm 25.3$ \\
\hline & & & & & OS $132.7 \pm 16.4$ & OS $63.6 \pm 14.1$ & OS $90.5 \pm 20.4$ & OS $130.9 \pm 15.0$ \\
\hline Stratus & Salchow 2006 & 92 & $9.7 \pm 2.7$ & $107.0 \pm 11.1$ & $135.4 \pm 19.3$ & $83.0 \pm 18.0$ & $72.5 \pm 13.4$ & $136.9 \pm 16.9$ \\
\hline Stratus & Huynh 2006 & 1369 & $6.7 \pm 0.4$ & $103.7 \pm 11.4$ & $129.5 \pm 20.6$ & $81.7 \pm 19.6$ & $75.7 \pm 14.7$ & $127.8 \pm 20.5$ \\
\hline Stratus & El-Dairi 2009 & 286 & $8.6 \pm 3.1$ & $108.3 \pm 9.9$ & $142.9 \pm 18.8$ & $83.3 \pm 19.2$ & $77.5 \pm 15.4$ & $129.4 \pm 18.3$ \\
\hline Stratus & Leung 2010 & 97 & $9.7(6.1-17.6)$ & $\begin{array}{l}\text { OD } 113.5 \pm 9.8 \\
\text { OS } 113.1 \pm 10.8\end{array}$ & $\begin{array}{l}\text { OD } 146.3 \pm 16.3 \\
\text { OS } 148.6 \pm 19.5\end{array}$ & $\begin{array}{l}\text { OD } 78.3 \pm 16.1 \\
\text { OS } 74.2 \pm 14.8\end{array}$ & $\begin{array}{l}\text { OD } 87.3 \pm 15.4 \\
\text { OS } 86.6 \pm 16.6\end{array}$ & $\begin{array}{l}\text { OD } 142.4 \pm 18.4 \\
\text { OS } 143.2 \pm 8.7\end{array}$ \\
\hline Stratus & Qian 2011 & 199 & $10.4 \pm 2.7$ & $112.3 \pm 9.2$ & $148.7 \pm 17.1$ & $74.8 \pm 15.0$ & $83.8 \pm 13.5$ & $142.1 \pm 16.0$ \\
\hline \multicolumn{9}{|l|}{ SD-OCT } \\
\hline Spectralis & Turk 2012 & 107 & $10.5 \pm 2.9$ & $106.4 \pm 9.4$ & $\begin{array}{l}\text { ST } 139.0 \pm 17.6 \\
\text { SN } 102.9 \pm 16.0\end{array}$ & $71.5 \pm 10.0$ & $74.3 \pm 9.4$ & $\begin{array}{l}\text { IT } 144.6 \pm 17.2 \\
\text { IN } 106.4 \pm 19.1\end{array}$ \\
\hline Spectralis & Yanni 2012 & 83 & $8.9(5-15)$ & $107.6 \pm 1.2$ & $\begin{array}{l}\text { ST } 145.1 \pm 2.2 \\
\text { SN } 116.2 \pm 2.8\end{array}$ & $84.5 \pm 1.9$ & $76.5 \pm 1.9$ & $\begin{array}{l}\text { IT } 147.0 \pm 2.1 \\
\text { IN } 125.4 \pm 3.0\end{array}$ \\
\hline RTVue-100 & Tsai 2012 & 470 & $9.2(6.5-12.5)$ & $109.4 \pm 10.0$ & $133.9 \pm 18.1$ & $71.1 \pm 11.3$ & $90.4 \pm 14.3$ & $142.2 \pm 19.5$ \\
\hline Cirrus & Elia 2012 & 344 & $9.2 \pm 1.7$ & $98.5 \pm 10.8$ & $123.6 \pm 19.5$ & $71.3 \pm 13.5$ & $69.4 \pm 11.3$ & $130.2 \pm 18.1$ \\
\hline Cirrus & Barrio-Barrio 2013 & 283 & $9.6 \pm 3.1$ & $97.4 \pm 9.0$ & 124.7 & 69.7 & 67.4 & 128.0 \\
\hline Cirrus & Al-Haddad 2013 current study & 108 & $10.7 \pm 3.1$ & $95.6 \pm 8.7$ & $120.6 \pm 13.8$ & $70.1 \pm 13.0$ & $66.4 \pm 8.9$ & $124.8 \pm 18.1$ \\
\hline
\end{tabular}

${ }^{*}$ mean \pm standard deviation or mean (range).
ST, supero-temporal; SN, supero-nasal; IT, infero-temporal; IN, infero-nasal. 


\section{Discussion}

This study reported normative values for RNFL thickness, macular thickness and macular volume in children 6-17 years of age using spectral domain OCT (Cirrus). Correlations with biometric data showed that central macular but not RNFL thickness values were higher in males; additionally, the macular inner circle thickness correlated positively with age and average RNFL thickness correlated positively with SE. Optical coherence tomography, being non-invasive and especially fast, is gaining more popularity in evaluating vitreoretinal diseases of childhood including pediatric glaucoma [20,22]. Spectral domain -OCT, the latest generation of the technology, provides higher resolution and decreased acquisition time, hence is more useful in the pediatric population. Direct comparison of RNFL and macular parameters between TD-OCT and SD-OCT is not possible due to different scanning algorithms [12-14]. Studies using the earlier TD-OCT in children have shown good reproducibility [4,23]. Altemir et al. showed good reliability and repeatability in children using Cirrus SDOCT [2]. With Stratus OCT, good quality scans could be obtained in $93 \%$ and $96 \%$ of children [1,3]. Using Spectralis SD-OCT, Turk et al. reported higher feasibility of $99 \%$ [16]. We similarly report high quality Cirrus OCT scans in $96 \%$ of our enrolled children.

Most available literature reporting normative OCT values in children used TD-OCT [5-11]. Recently, normal values have been reported using Spectralis in Turkish and North American children [16,17] and RTVue-100 OCT in Chinese children [18]. Using Cirrus, Elia et al. reported RNFL but not macular parameters in Caucasian children aged 6-13 years; however, ophthalmologic examination was performed without cycloplegia and OCT parameters were not correlated with biometric data [19]. Our work compliments the latter study by: confirming RNFL normative values on Cirrus, expanding the age group to include 14-17 year-old adolescents, reporting additional normative values for macular thicknesses and volume, and correlating RNFL and macular parameters with age, gender, refractive error and axial length. At the time of our data analysis, we noted a recent report of similar work using Cirrus in another study from Spain; Barrio-Barrio et al. reported RNFL and macular measurements in Caucasian children from three Spanish centers [21]. While Elia and Barrio-Barrio reported normative values in the Spanish population, the current study reported normative Cirrus OCT values in children from the Middle East. The study by Barrio-Barrio tried to address similar objectives as the current study; differences in design include the multicenter nature of their study and the different age group (4-17 years in their study, 6-17 years in our study). Reported normative data in their study were very close to our measurements (Tables 4 \& 5), correlations were also in agreement: positive correlation of RNFL with SE and central macular thickness with age and male gender. They similarly excluded subjects with high refractive errors ( $>5.5$ diopters of SE).

Tables 4 and 5 compare our OCT values with earlier literature. Average RNFL thickness in this study measured $96 \mu \mathrm{m}$ comparable to others using Cirrus (97-98 $\mu \mathrm{m})$ but lower than values recorded using Stratus $(104-113 \mu \mathrm{m})$, Spectralis $(106-107 \mu \mathrm{m})$ and RTVue $(109 \mu \mathrm{m})$. The quadrant thickness distribution followed the classic "double hump" pattern seen in adults with the thickest being the inferior followed by the superior then nasal and temporal, consistent with the "ISNT rule". However, a number of reports have shown exceptions to this rule $[3,5,7,9,18]$.

Macular parameters show the greatest variability among different OCT devices and algorithms [14]; discrepancies have also been noted across different versions of OCT $[15,24]$. Few studies have reported macular parameters in normal children (Table 5). Mean macular volume in our study was $10.1 \mathrm{~mm}^{3}$ similar to other studies using Cirrus but much higher than those obtained by Stratus $\left(7 \mathrm{~mm}^{3}\right)$ or Spectralis $\left(0.25 \mathrm{~mm}^{3}\right)$; this also applied to central

Table 5 Reported macular thickness measurements by optical coherence tomography in normal children

\begin{tabular}{|c|c|c|c|c|c|c|c|}
\hline \multirow[b]{2}{*}{ OCT } & \multirow[b]{2}{*}{ Source } & \multirow[b]{2}{*}{ n } & \multirow[b]{2}{*}{$\begin{array}{l}\text { Age, } \\
\text { years* }\end{array}$} & \multicolumn{4}{|c|}{ Macular parameters* } \\
\hline & & & & Volume, $\mathrm{mm}^{3}$ & Averag & ess, $\mu \mathrm{m}$ & Central thickness, $\mu \mathrm{m}$ \\
\hline \multicolumn{8}{|l|}{ TD-OCT } \\
\hline Stratus & Huynh 2006 & 1543 & $6.7 \pm 0.4$ & $6.9 \pm 0.4$ & Inner: $264.3 \pm 15.2$ & Outer: $236.9 \pm 13.6$ & $193.6 \pm 17.9$ \\
\hline Stratus & El-Dairi 2009 & 286 & $8.6 \pm 3.1$ & $6.9 \pm 0.3$ & Inner: $268.3 \pm 13.6$ & Outer: $240.0 \pm 12.8$ & $188.8 \pm 25.0$ \\
\hline Stratus & Eriksson 2009 & 56 & $10.1(5-16)$ & $7.1 \pm 0.3$ & Inner: $279 \pm 13$ & Outer: $245 \pm 12$ & $204 \pm 19$ \\
\hline \multicolumn{8}{|l|}{ SD-OCT } \\
\hline Spectralis & Turk 2012 & 107 & $10.5 \pm 2.9$ & $0.26 \pm 0.01$ & \multicolumn{2}{|c|}{$326.4 \pm 14.2$} & $211.4 \pm 12.2$ \\
\hline Cirrus & Barrio-Barrio 2013 & 281 & $9.6 \pm 3.12$ & $10.2 \pm 0.5$ & \multicolumn{2}{|c|}{$283.6 \pm 14.1$} & $253.9 \pm 19.8$ \\
\hline Cirrus & $\begin{array}{l}\text { Al-Haddad } 2013 \\
\text { current study }\end{array}$ & 108 & $10.7 \pm 3.14$ & $10.1 \pm 0.5$ & \multicolumn{2}{|c|}{$279.6 \pm 12.5$} & $249.1 \pm 20.2$ \\
\hline
\end{tabular}

*mean \pm standard deviation or mean (range). 
macular thickness values. Average macular thickness was highest on Spectralis $(326 \mu \mathrm{m})$, followed by Cirrus (280$284 \mu \mathrm{m})$ and Stratus $(240-270 \mu \mathrm{m})$. Yanni et al. reported mean macular thickness $(271 \mu \mathrm{m})$ on Spectralis but proceeded to segment the retinal layers and perform normative segmentation values, hence their data were not included in Table 5 [17]. In the current study, inner macular thicknesses were statistically significantly higher than outer macular values in all quadrants similar to results from Stratus [4,5].

Discrepancies noted in recorded normative OCT values could also be related to confounding variables like ethnicity, race, gender, age, SE and AL measurements. All our subjects were white and Middle Eastern while the other two reports using Cirrus came from a Spanish population. Gender differences applied only in central macular thickness measurements which were significantly increased in males. This finding is in agreement with Barrio-Barrio [21] and Huynh et al. [8]. Gender differences may need to be accounted for during OCT interpretations.

In this study, RNFL values were not affected by age in agreement with other reports [5,9,16,21]. Some authors suggested that nerve fiber layer losses happened later in life after the age of 50 years, hence the absence of RNFL correlation with age in children [25]. By contrast, we found a strong positive correlation between age and macular parameters, similar to the findings by BarrioBarrio et al. [21] and Huynh et al. [8].

High refractive errors may affect OCT measurements; therefore, we excluded patients with SE more than 7 diopters. Still we noted a strong persistent positive correlation between SE and average RNFL thickness measurements after controlling for axial length. Many authors have observed positive correlations with $\mathrm{SE}[3,8,11,18]$. Tsai et al. reported an increase in average RNFL thickness of $1.7 \mu \mathrm{m}$ for every diopter of hyperopia [18]. On the other hand, Turk et al. did not detect any correlations with SE or axial length [16].

Strengths of this study include the large age range (6-17 years) of enrolled children, the use of the new generation Cirrus SD-OCT, the completion of a comprehensive eye examination (with cycloplegic retinoscopy) by a pediatric ophthalmologist, the recording of both normative RNFL and macular parameters, and the detailed biometric correlations. Limitations of this work include the mostly uniform ethnic group (white and Middle Eastern) so the effect of race and ethnicity could not be tested. We also excluded patients with high refractive errors and increased cup to disc ratios; normative data for these groups were not established. Additionally, our study was hospitalbased and not population-based. However, patients in this setting received a comprehensive examination, and biometric data were recorded.

\section{Conclusions}

This study established normal reference ranges for RNFL and macular parameters measured by Cirrus SD-OCT in healthy Middle Eastern children 6-17 years of age. This adds another database to the available literature on normative values using other OCT devices and facilitates evaluation of OCT measurements in children with optic neuropathies, glaucoma and macular diseases. The data presented are for white Middle Eastern children; hence, other races and ethnicities should be studied in future research. Variability with age and gender warrants special consideration during OCT interpretations.

\section{Competing interests}

The authors declare that they have no competing interests.

\section{Authors' contributions}

CA conceived and designed the study and drafted the manuscript. $A B$ participated in enrolling patients, analyzing results and drafting the manuscript. MJ enrolled patients, analyzed results and drafted the manuscript. VM enrolled patients and analyzed results and drafted the manuscript. HT participated in study design,statistical analysis and drafting the manuscript. BN participated in study conception, design and analysis of results. All authors reviewed the final manuscript critically and approved it. All authors read and approved the final manuscript.

\section{Author details}

${ }^{1}$ Department of Ophthalmology, American University of Beirut, Beirut, Lebanon. ${ }^{2}$ Department of Internal Medicine, American University of Beirut, Beirut, Lebanon.

Received: 11 July 2013 Accepted: 27 February 2014

Published: 22 April 2014

\section{References}

1. Leung CK, Cheung CY, Weinreb RN, Qiu Q, Liu S, Li H, Xu G, Fan N, Huang L, Pang CP, Lam DS: Retinal nerve fiber layer imaging with spectral-domain optical coherence tomography: a variability and diagnostic performance study. Ophthalmology 2009, 116:1257-1263.

2. Altemir I, Pueyo V, Elía N, Polo V, Larrosa JM, Oros D: Reproducibility of optical coherence tomography measurements in children. Am J Ophthalmol 2013, 155:171-176.

3. Salchow DJ, Oleynikov YS, Chiang MF, Kennedy-Salchow SE, Langton K, Tsai JC, Al-Aswad LA: Retinal nerve fiber layer thickness in normal children measured with optical coherence tomography. Ophthalmology 2006, 113:786-791.

4. Eriksson U, Holmström G, Alm A, Larsson E: A population-based study of macular thickness in full-term children assessed with Stratus OCT: normative data and repeatability. Acta Ophthalmol 2009, 87:741-745.

5. El-Dairi MA, Asrani SG, Enyedi LB, Freedman SF: Optical coherence tomography in the eyes of normal children. Arch Ophthalmol 2009, 127:50-58.

6. Leung MM, Huang RY, Lam AK: Retinal nerve fiber layer thickness in normal Hong Kong Chinese children measured with optical coherence tomography. J Glaucoma 2010, 19:95-99.

7. Huynh SC, Wang XY, Rochtchina E, Mitchell P: Peripapillary retinal nerve fiber layer thickness in a population of 6-year-old children: findings by optical coherence tomography. Ophthalmology 2006, 113:1583-1592.

8. Huynh SC, Wang XY, Rochtchina E, Mitchell P: Distribution of macular thickness by optical coherence tomography: findings from a populationbased study of 6-year-old children. Invest Ophthalmol Vis Sci 2006, 47:2351-2357

9. Ahn HC, Son HW, Kim JS, Lee JH: Quantitative analysis of retinal nerve fiber layer thickness of normal children and adolescents. Korean J Ophthalmol 2005, 19:195-200.

10. Ecsedy M, Szamosi A, Karkó C, Zubovics L, Varsanyi B, Nemeth J, Rescan Z A comparison of macular structure imaged by optical coherence 
tomography in preterm and full-term children. Invest Ophthalmol Vis Sci 2007, 48:5207-5211.

11. Qian J, Wang W, Zhang X, Wang F, Jiang Y, Wang W, Xu S, Wu Y, Su Y, Xu $X$, Sun $X$ : Optical coherence tomography measurements of retinal nerve fiber layer thickness in chinese children and teenagers. J Glaucoma 2011, 20:509-513.

12. Seibold LK, Mandava N, Kahook MY: Comparison of retinal nerve fiber layer thickness in normal eyes using time-domain and spectral-domain optical coherence tomography. Am J Ophthalmol 2010, 150:807-814.

13. Knight OJ, Chang RT, Feuer WJ, Budenz DL: Comparison of retinal nerve fiber layer measurements using time domain and spectral domain optical coherent tomography. Ophthalmology 2009, 116:1271-1277.

14. Geitzenauer W, Kiss CG, Durbin MK, Abunto MT, Callan TM, Stetson PF, Wieland MR, Bressier NM, Gregori G, Schmidt-Erfurth UM: Comparing retinal thickness measurements from Cirrus spectral domain- to Stratus time domain- optical coherence tomography. Retina 2010, 30:596-606.

15. Kanamori A, Nakamura M, Tomioka M, Kawaka Y, Yamada Y, Negi A: Agreement among three types of spectral-domain optical coherent tomography instruments in measuring parapapillary retinal nerve fibre layer thickness. Br J Ophthalmol 2012, 96:832-837.

16. Turk A, Ceylan OM, Arici C, Keskin S, Erdurman C, Durukan AH, Mutlu FM, Altinsoy $\mathrm{Hl}$ : Evaluation of the nerve fiber layer and macula in the eyes of healthy children using spectral-domain optical coherence tomography. Am J Ophthalmol 2012, 153:552-559.

17. Yanni SE, Wang J, Cheng CS, Locke KI, Wen Y, Birch DG, Birch EE: Normative reference ranges for the retinal nerve fiber layer, macula, and retinal layer thicknesses in children. Am J Ophthalmol 2013, 155:354-360.

18. Tsai DC, Huang N, Hwu JJ, Jueng RN, Chou P: Estimating retinal nerve fiber layer thickness in normal schoolchildren with spectral-domain optical coherence tomography. Jpn J Ophthalmol 2012, 56:362-370.

19. Elía N, Pueyo V, Altemir I, Oros D, Pablo LE: Normal reference ranges of optical coherence tomography parameters in childhood. Br J Ophthalmol 2012, 96:665-670.

20. Hess DB, Asrani SG, Bhide MG, Enyedi LB, Stinnett SS, Freedman SF: Macular and retinal nerve fiber layer analysis of normal and glaucomatous eyes in children using optical coherence tomography. Am J Ophthalmol 2005, 139:509-517.

21. Barrio-Barrio J, Noval S, Galdós M, Ruiz-Canela M, Bonet E, Capote M, Lopez M: Multicenter Spanish study of spectral-domain optical coherence tomography in normal children. Acta Ophthalmol 2013, 91:56-63.

22. Salchow DJ, Hutcheson KA: Optical coherence tomography applications in pediatric ophthalmology. J Pediatr Ophthalmo/ Strabismus 2007, 44:335-349

23. Wang XY, Huynh SC, Burlutsky G, Ip J, Stapleton F, Mitchell P. Reproducibility of and effect of magnification on optical coherence tomography measurements in children. Am J Ophthalmol 2007, 143:484-488.

24. Pierre-Kahn V, Tadayoni R, Haouchine B, Massin P, Gaudric A: Comparison of optical coherence tomography models OCT 1 and Stratus OCT for macular and retinal thickness measurement. $\mathrm{Br} J$ Ophthalmol 2005, 89:1581-1585

25. Parikh RS, Parikh SR, Sekhar GC, Prabakaran S, Babu JG, Thomas R: Normal age-related decay of retinal nerve fiber layer thickness. Ophthalmology 2007, 114:921-926

\section{Submit your next manuscript to BioMed Central and take full advantage of:}

- Convenient online submission

- Thorough peer review

- No space constraints or color figure charges

- Immediate publication on acceptance

- Inclusion in PubMed, CAS, Scopus and Google Scholar

- Research which is freely available for redistribution

Submit your manuscript at www.biomedcentral.com/submit
Ciomed Central 